Egyptian Journal of Radiation
Sciences and Applications
http://ejrsa.journals.ekb.eg/

\title{
Evaluation of MicroRNA-16 and MicroRNA-221 in Serum and \\ Placenta in Gestational Diabetes Mellitus: Correlation with Macrosomia
}

Elham Sayed Marei\#, Hanan Mohamed Gabr Youssef

Health Radiation Research Department, National Center for Radiation Research and Technology, Egyptian Atomic Energy Authority, Cairo, Egypt.

\begin{abstract}
CESTATIONAL diabetes mellitus (GDM) is associated with short and long-term Complications for pregnant women and their coming offspring. MicroRNAs are small noncoding RNA molecules that regulate gene expression. This study aimed to investigate the potential expression of microRNA-16 and 221 in maternal serum and their mirror expression in the placenta in GDM and their correlation with severity of GDM and Macrosomia.

This study was conducted on twenty pregnant women with GDM and other twenty healthy pregnant women who served as a control group. GDM group was further subdivided into severe and mild subgroups according to the levels of fasting and postprandial 2 hours glucose levels. MicroRNA-16 and microRNA-221 were estimated by quantitative real time polymerase chain reaction (qRT-PCR). Results revealed that microRNA-16 levels in serum and placental tissue were significantly higher in the GDM group than the control group, with high significant increase in severe GDM than in mild GDM subgroup. Significant decreases in the levels of microRNA-221 were detected in both serum and placenta in GDM group versus the control group. In GDM group, there was a direct high significant correlation of microRNA-16 in serum and placenta with fetal macrosomia, but there was no correlation of microRNA-221 in serum with fetal macrosomia.A significant increase of microRNA-16 in the severe GDM group than in the mild GDM group was observed and it could be concluded that microRNA-16 may be the noncoding RNA at the molecular level that affected the severity of GDM in mothers and the macrosomia of their offspring.
\end{abstract}

Keywords: GDM, Macrosomia, MicroRNA-16, MicroRNA-221, Placental tissue, Serum.

\section{Introduction:}

Gestational diabetes mellitus is defined as impaired glucose tolerance diagnosed during pregnancy for the first time and is present in $6-7 \%$ of pregnancies with the increase in pregnancy complications (Catalano, 2014). It is one of the most common medical disorders of pregnancy. Women with GDM are at high risk for future type 2 diabetes, $50 \%$ of women with GDM subsequently develop type 2 diabetes within 25 years (England et al., 2009; O’Sullivan, 1982). Additionally, maternal diabetes during pregnancy exposes the fetus to hyperglycemia and high insulin levels, which might be related to increased risk of childhood and adult obesity; type 2 diabetes and GDM at childbearing ages (Dabelea et al., 2000).

There are series of metabolic changes that occur during normal pregnancy, with a progressive increase in insulin resistance mainly due to placental hormones production (growth hormone, progesterone, placental lactogen, and corticotrophin) important for fetal nutrition. Gestational diabetes develops in women whose insulin production is insufficient to counteract increasing insulin resistance (Catalano, 2014) that has been correlated with increasing of maternal

${ }^{\#}$ Corresponding author e-mail: elhammarei@yahoo.com

Received 11/12/2020; Accepted 5/1/2021

DOI: $10.21608 /$ ejrsa.2021.53195.1110

C2020 National Information and Documentation Center (NIDOC) 
age and obesity (Lawrence et al., 2008; Ferrara, 2007).

Gestational diabetes mellitus occurs when the function of pancreatic $\beta$ cells is insufficient to overcome the insulin resistance that occurs during pregnancy (Basina, 2012). The oral glucose tolerance test (OGTT) is still the golden standard for the identification of this disorder. However, the cut-off values established by the World Health Organization (WHO) have been modified by some international associations, generating multiple measures for the diagnosis and management of GDM (Akgöl et al., 2017).

Oral glucose tolerance test (OGTT) is commonly used to diagnose GDM in clinical practice, but this test is usually performed at 24-28 weeks of pregnancy, and sometimes is delayed until 32 weeks. This leaves little time to change diet and exercise regimens, or for medical intervention, and increases the risk and complications of GDM in later pregnancies. Hence, there is a need for prompt strategies for early diagnosis of GDM (Rodrigo \& Glastras, 2018; Karcaaltincaba et al., 2017).

The expression of microRNAs has been reported to be associated with pregnancy related diseases as GDM and pre-eclampsia. Maternalfetal cellular communication depends on factors secreted by the placenta, which could be used as markers of altered placental functions, which are detectable in the maternal circulation from the early stages of pregnancy; and therefore could have a predictive value in various pregnancy-related diseases (Ilekis et al., 2016). Several studies were conducted to identify biomarkers and to make a timely diagnosis of GDM (Karcaaltincaba et al., 2017; Powe, 2017).

The human placenta expresses $>500$ microRNAs, almost exclusively expressed in this organ. For this reason, the study of placental microRNAs is essential for the understanding of the regulatory mechanisms of normal and complicated pregnancies (Guarino et al., 2018).

MicroRNAs are small noncoding RNAs with 18-22 nucleotides, which have been described to control post-transcriptional gene expression through binding of the translation section, and leading to either microRNAs deprivation or translational inhibition (Krol et al., 2010). Pre-
miRNA depends on the transportation mechanism to reach the cytoplasm and then it is cut into a mature 22 nucleotides chain microRNA with the Dicer. The twofold stranded microRNA is made after the creation of the Argonaute proteins (Agos) family (Bartel, 2009), which precisely relay with small RNAs and considered to be the main of all known RNA-induced silencing complexes (RISCs). These proteins are functionally specified into distinct RNA silencing pathways. ( $\mathrm{Su}$ et al., 2009). Mammals contain four copies of Ago genes: Ago1-Ago4, (Song et al., 2004), (AGO1, $A G O 3$ and $A G O 4$ ) are existing as tandem copies in the similar orientation on human chromosome 1p34.3, while $A G O 2$ exists on its own on human chromosome 8q24.3. Only Ago2 has cleavage activity that target mRNAs directed by smallinterfering RNAs (siRNAs) (Yekta et al., 2004). Ago1, Ago3 and Ago4 most likely have misplaced this cleavage function and instep exclusively depending on a non-cleavage mechanism to actuate translational restraint of target mRNAs by means of miRNAs (Wang et al., 2009).

The expression of microRNAs has been reported to be associated with pre-eclampsia and GDM (Pillar et al., 2015). In their study, Cao and colleagues reported that plasma microRNA$16-5 p$ was significantly upregulated at different times during pregnancy in GDM compared with non-GDM women and reflected a clear separation between GDM and non-GDM patients (Cao et al., 2017).

Li et al. (2009) in their study suggested that during the development of diabetes, hyperglycemia,a malfunction of the vasculature may be induced. Exposure to high levels of glucose may alter microRNAs expression in cardiovascular cells under many pathological conditions. They identified a novel pathway by which hyperglycemic conditions impair c-kit expression and migration of human umbilical vein endothelial cells, perhaps through induction of microR-221, and they reported that manipulation of the microR-221-c-kit path might propose a new approach for management of vascular dysfunction in diabetic patients ( $\mathrm{Li}$ et al., 2009). In several studies, the authors related upregulated microRNA-221 to asymptomatic carotid stenosis (Dolz et al., 2017), focal cerebral ischemia (Gusar et al., 2017), pulmonary artery hypertension (Nie et al., 2019) and obesity (Villard et al., 2015). Its upregulation is related to cardiac amyloidosis 
(Derda et al., 2018), heart failure (Verjans et al., 2018), aortic stenosis (Zhuang et al., 2019), acute myocardial infarction (Coskunpinar et al., 2016), acute ischemic stroke (Sørensen et al., 2014) and atherosclerosis (Pereira-da-Silva et al., 2018).

Previous studies (Guarino et al., 2018) have suggested that microRNAs are involved in GDM; however, the microRNA-16 and microRNA-221 expression in serum and placental tissues from GDM patients and their significance to macrosomia of the offspring, to our knowledge, have not been evaluated. For this reason, this study was conducted aiming to determinate and evaluate the association of microRNA-16 and microRNA-221 expression in gestational diabetes mellitus and to find the correlation between serum, placental microRNA-16 and microRNA-221 with macrosomia associated with Gestational diabetes mellitus.

\section{Materials and Methods}

\section{Study setting and study population}

The study involved forty Egyptian pregnant women who attend Ain Shams University Hospital, Obstetrics and Gynecology Department, at labor wards. 20 pregnant women who were previously diagnosed as gestational diabetic patients were recruited for the study with mean age of $(29.02 \pm 2.244)$ years, in addition, 20 pregnant women without GDM (control group) with mean age of $(28.8 \pm 2.375)$ years were also recruited. Pregnant women with GDM were further classified into mild $(n=12)$ and severe $(n=8)$ subgroups in accordance to the 2-hours oral glucose tolerance test which was initially proposed by the International Association of Diabetes and Pregnancy. Study Groups: Patients with the following criteria were excluded: (1) Prepregnancy diabetes mellitus; (2) Severe systemic disease; (3) Family history of known congenital or chromosomal abnormalities of the fetus; (4) Age $<18$ years; (5) Twin pregnancies. All the participants were interviewed and personal data were collected and all of them agreed to be part of the study and gave informed consents preliminary to the study according to Helsinki declaration.

\section{Data collection}

All participants were subjected to clinical examinations with measurements of the systolic and diastolic blood pressures. The laboratory investigations (hemoglobin, platelets, urine albumin, ALT, AST, creatinine, urea, cholesterol, FBS, postprandial blood sugar and INR) were performed for all subjects. Blood samples were collected on admission for labor; serum was separated and collected in aliquots and stored at $-80^{\circ} \mathrm{C}$ until further processing. All placental samples were washed with saline and stored at $-80^{\circ} \mathrm{C}$.

Parameters such as personal and family history of diabetes, type of delivery, complications of pregnancy, body mass index and perinatal data, as well as data regarding the infants' APGAR scores, weight and sex were taken prospectively from women joined in the trial after informed consent.

"Macrosomia" implies growth beyond an absolute birth weight, historically 4,000 gm. Excessive fetal growth is described as "large for gestational age which means a birth weight equal to or more than the 90th percentile for a given gestational age" (ACOG Practice Bulletin, 2010).

Body mass index (BMI) was calculated in this study by detecting patients weight in kilograms divided by the square of height in meters. Serum insulin concentrations were measured by radioimmunoassay (RIA) using a commercial kit, DIA source INS-IRMA kit, supplied by DIA source ImmunoAssays S.A. (Belgium). For test investigation by RIA, a porcine-specific one-site insulin RIA2 was utilized. This test is based on 125I-labeled insulin and utilized guinea pig antiporcine insulin antibodies and goat anti-guinea pig IgG antibodies. Decontaminated human recombinant insulin preparations were utilized as guidelines for calibration. The manufacturer's procedure referred to the assay's restrain of linearity of $200 \mu \mathrm{IU} / \mathrm{mL}$ and prescribed dilution of the samples, which have more noteworthy concentrations with the test buffer. The limit of recognition for this measure is $1.61 \mu \mathrm{IU} / \mathrm{mL}$ when $100 \mu \mathrm{l}$ of test is utilized. The cross-reactivity of the test is expressed at $100 \%$ for porcine insulin, 100\% for human insulin and $90 \%$ for bovine insulin.

\section{GDM diagnosis}

$\mathrm{HbA}$ lc should be used in association with other standard diagnostic tests for GDM diagnosis (Renz et al., 2019). The HbA1c analysis was performed using high-pressure liquid chromatography on a Bio-Rad Variant II instrument.

OGTT was performed after an overnight fast 
of $10 \mathrm{~h}$. A sample was taken at baseline and then the patient consumed a dose of $75 \mathrm{~g}$ glucose. The patient was required to finish the whole volume in 5 min of starting the drink. Blood samples were taken at 1 and $2 \mathrm{~h}$ after starting dextrose drink and measured using the Abbott glucose hexokinase method on an Architect C8000 analyzer (Abbott Australasia Pty Ltd).

Normal results for gestational diabetes:

- Fasting glucose level below $90 \mathrm{mg} / \mathrm{dL}$

- One-hour glucose level below 130 to $140 \mathrm{mg} / \mathrm{dL}$

- Two-hour glucose level below $120 \mathrm{mg} / \mathrm{dL}$

Abnormal results for gestational diabetes:

- Fasting glucose level greater than $95 \mathrm{mg} / \mathrm{dL}$

- One-hour glucose level greater than $140 \mathrm{mg} / \mathrm{dL}$

- Two-hour glucose level greater than 120 mg/dL (Eyth et al., 2020; Li \& Yu, 2019)

RNA extraction and Polymerase Chain Reaction

Total RNA was extracted from $25 \mathrm{mg}$ of placental tissue preserved in RNA later (Ambion) followed by an enrichment procedure for small RNAs (siRNAs, microRNAs), according to the manufacturer's instructions using a mirVana microRNA Isolation kit (Ambion). Total RNAs were isolated from all samples using miRNeasy Serum/Plasma Kit (Qiagen, Germany) according to the manufacturer's instructions. Singlestranded cDNA was prepared in a reversetranscription reaction using TaqMan MicroRNA Reverse Transcription Kit (Thermo Fisher, USA) using $5 \mu \mathrm{g}$ of RNA, according to the manufacturer's protocol. The cycling condition for cDNA synthesis included incubation of the reaction mixture at $25^{\circ} \mathrm{C}$ for $10 \mathrm{~min}, 42^{\circ} \mathrm{C}$ for 60 min, followed by $10 \mathrm{~min}$ at $70^{\circ} \mathrm{C}$.

PCR was carried out using cDNA, $\mathrm{MgCl}$ (10 $\mathrm{mM}$ ) to improve the DNA intensification by enhancing the action of Taq DNA polymerase.,
Taq-polymerase (5 U/ $\mu \mathrm{l})$, PCR buffer, dNTP $(10 \mathrm{mM})$ and a pair of specific primers $(10 \mu \mathrm{M})$ as shown in Table 1 in a final volume of $20 \mu \mathrm{l}$ each tube. The PCR conditions were as follows: initial denaturation at $95^{\circ} \mathrm{C}$ for $5 \mathrm{~min}$ followed by 40 cycles, annealing at $95^{\circ} \mathrm{C}$ for $15 \mathrm{~s}$, and extension at $60^{\circ} \mathrm{C}$ for $20 \mathrm{~s}$ and final extension at $72^{\circ} \mathrm{C}$ for $40 \mathrm{~s}$. Relative expression of studied miRNA was calculated using the comparative $\mathrm{Ct}$ method. All values were normalized to U6, which was used as the control housekeeping gene and reported as fold change.

\section{Statistical analysis}

It was performed using SPSS version 20 statistical software (SPSS, Inc, Chicago, IL) and a $\mathrm{P}$ value of $<0.05$ was considered statistically significant. All the results were defined as mean \pm standard deviation. The independent sample-t test was applied to compare the microRNAs expression levels, and the other measured parameters between GDM group and healthy control group. One-way ANOVA test was applied for comparison between mild GDM, severe GDM subgroups and control group.

\section{$\underline{\text { Results }}$}

Table 2 shows that there were highly significant differences in $\mathrm{FBG}, \mathrm{PPG}, \mathrm{HbA} 1 \mathrm{c}$, fasting insulin, gestational age, fetal birth weight between the two groups studied. Serum and placental microRNA-16 in GDM group increased significantly as compared to control group, serum and placental microRNA-221 in GDM group decreased significantly than control group.

Table 3 shows that in the GDM group, there was a positive significant correlation between serum and placental microRNA-16 with FBG, BMI, and fetal birth weight, while an inverse significant correlation between serum microRNA-221 and FBG, PPG was detected.

TABLE1. The primer sequence of the studied microRNAs

\begin{tabular}{ll}
\hline & Primer sequence \\
\hline MicroRNA-221 & Forward primer :5'- TGCCTCCAACTGACTCCTAC -3 \\
& Reverse primer 5'- GCGAGCACAGAATAATACGAC CC -3 \\
MicroRNA-16 & Forward primer :5'- CGGTGTCGTAGTTGAAGTGAG -3 \\
& Reverse primer 5'- GATGTCGGATCCGTCTGAGC -3 \\
U6 & Forward :5 CTCGCTTCGGCAGCACA - 3' \\
& Reverse: 5- AACGCTTCACGAATTTGCGT -3 \\
\hline
\end{tabular}


TABLE 2.The Demographic data and laboratory investigations of control group compared to gestational diabetes group

\begin{tabular}{|c|c|c|c|}
\hline Parameters & $\begin{array}{l}\text { Control }(n=20) \\
\text { Mean } \pm \text { SD }\end{array}$ & $\begin{array}{c}\text { Gestational Diabetes }(n=20) \\
\text { Mean } \pm \text { SD }\end{array}$ & $P$ values \\
\hline Age (years) & $28.8 . \pm 2.375$ & $29.02 \pm 2.244$ & 0.053 \\
\hline Parity & $1.80 \pm 0.768$ & $2.10 \pm 0.960$ & 0.227 \\
\hline BMI & $29.63 \pm 2.66$ & $32.21 \pm 4.06$ & $0.023^{*}$ \\
\hline Fasting Blood glucose & $81.60 \pm 5.404$ & $194.00 \pm 60.242$ & $0.0001 * *$ \\
\hline Postprandial glucose & $118.3 \pm 11.926$ & $243.40 \pm 63.446$ & $0.0001 * *$ \\
\hline $\mathrm{HbA1c}$ & $4.20 \pm 0.458$ & $8.18 \pm 1.58$ & $0.0001 * *$ \\
\hline Fasting Insulin $(\mu \mathrm{lU} / \mathrm{ml})$ & $5.76 \pm 1.89$ & $18.93 \pm 3.72$ & $0.0001 * *$ \\
\hline Systolic BP (mmHg) & $112.00 \pm 19.19$ & $118.5 \pm 16.66$ & 0.353 \\
\hline Diastolic BP (mmHg) & $71.30 \pm 12.24$ & $75.5 \pm 9.30$ & 0.551 \\
\hline Gestational age (weeks) & $38.6 \pm 0.94$ & $36.1 \pm 3.47$ & $0.01^{*}$ \\
\hline Fetal birth weight(gm) & $3260.5 \pm 231.16$ & $3955.00 \pm 416.09$ & $0.001 * *$ \\
\hline Urine albumin(gm/dl) & 0 & $1.05 \pm 0.25$ & $0.01 *$ \\
\hline Hemoglobin (gm/dl) & $11.86 \pm 1.721$ & $11.70 \pm 1.306$ & 0.634 \\
\hline ALT(U/L) & $31.40 \pm 10.25$ & $35.00 \pm 7.59$ & 0.215 \\
\hline $\operatorname{AST}(\mathrm{U} / \mathrm{L})$ & $34.80 \pm 8.14$ & $35.40 \pm 2.79$ & 0.918 \\
\hline Urea (mg/dl) & $21.20 \pm 4.65$ & $25.40 \pm 7.59$ & 0.054 \\
\hline Creatinine(mg/dl) & $0.910 \pm 0.384$ & $0.921 \pm 0.339$ & 0.855 \\
\hline Platelet count $\left(\times 10^{3} / \mathrm{ul}\right)$ & $380.40 \pm 75.37$ & $391.20 \pm 82.13$ & 0.667 \\
\hline INR & $1.14 \pm 0.104$ & $1.00 \pm 0.194$ & $0.07 *$ \\
\hline $\operatorname{TLC}\left(\times 10^{3} / \mathrm{ul}\right)$ & $6680 \pm 2018$ & $7010 \pm 1704$ & 0.591 \\
\hline $\begin{array}{l}\text { Serum MicroRNA-221 } \\
\text { (relative expression) }\end{array}$ & $1.016 \pm 0.019$ & $0.550 \pm 0.181$ & $0.0001 * *$ \\
\hline $\begin{array}{l}\text { Placenta MicroRNA-221 } \\
\text { (relative expression) }\end{array}$ & $1.006 \pm 0.012$ & $0.210 \pm 0.048$ & $0.0001 * *$ \\
\hline $\begin{array}{l}\text { Serum MicroRNA-16 } \\
\text { (relative expression) }\end{array}$ & $1.014 \pm 0.015$ & $3.702 \pm 1.474$ & $0.0001 * *$ \\
\hline $\begin{array}{l}\text { Placenta MicroRNA-16 } \\
\text { (relative expression) }\end{array}$ & $1.030 \pm 0.038$ & $5.182 \pm 0.940$ & $0.0001 * *$ \\
\hline Cesarean Section (\%) & $10(50 \%)$ & $12(60 \%)$ & 0.205 \\
\hline
\end{tabular}

*: Significant if $(\mathrm{P}<0.05), * *$ : High significant if $(\mathrm{P}<0.001)$.

Table 4 shows that in both groups, there was high a significant correlation between serum \& placental microRNA-16 with fetal birth weight, FBG, PPG, and BMI, while a high significant inverse correlation between serum\& placental microRNA-221 with fetal birth weight, FBG, PPG was detected.

Table 5 shows highly significant differences in mean FBG, PPG, cholesterol, fetal birth weight, serum and placental microRNA-16 and microRNA-221 and significant difference in BMI between the mild, severe gestational diabetes and control group.

Table 6 clarifies significant differences in FBG, PPG, HbA1c, fetal birth weight, creatinine, serum \&placental microRNA-16 and serum microRNA-221 between mild and severe gestational diabetes. 
TABLE 3. Correlation between Serum and placental MicroRNA-16 and MicroRNA-221 with Fetal weight, FBS, PPG, BMI in gestational diabetes group $(n=20)$

\begin{tabular}{lccccc}
\hline Parameter & & Fetal weight & FBS & PPG & BMI \\
\hline \multirow{2}{*}{ Serum } & Correlation coefficient & 0.435 & 0.508 & 0.428 & 0.865 \\
MicroRNA-16 & P value & $0.05^{*}$ & $0.02^{*}$ & $0.05^{*}$ & $0.0001^{* *}$ \\
& GDM group N= & 20 & 20 & 20 & 20 \\
Placenta & Correlation coefficient & 0.778 & 0.855 & 0.869 & 0.134 \\
MicroRNA-16 & P value & $0.0001^{* *}$ & $0.0001^{* *}$ & $0.0001^{* *}$ & 0.57 \\
& GDM group N= & 20 & 20 & 20 & 20 \\
Serum & Correlation coefficient & -0.097 & -0.650 & -0.741 & -0.245 \\
MicroRNA-221 & P value & .683 & $0.002^{* *}$ & $0.0001^{* *}$ & 0.298 \\
& GDM group N= & 20 & 20 & 20 & 20 \\
Placenta & Correlation coefficient & -0.025 & -0.327 & -0.123 & 0.796 \\
MicroRNA-221 & P value & 0.918 & 0.16 & 0.604 & $0.0001^{* *}$ \\
& GDM group N= & 20 & 20 & 20 & 20 \\
\hline
\end{tabular}

*: Significant if $(\mathrm{P}<0.05), * *$ : High significant if $(\mathrm{P}<0.001)$.

TABLE 4. Correlation between Serum and placental MicroRNA-16 and MicroRNA-221 with Fetal weight, FBS, PPG, BMI in both studied groups $(n=40)$

\begin{tabular}{|c|c|c|c|c|c|}
\hline Parameter & & Fetal weight & FBS & PPG & BMI \\
\hline \multirow{3}{*}{$\begin{array}{l}\text { Serum } \\
\text { MicroRNA-16 }\end{array}$} & Correlation coefficient & 0.563 & 0.459 & 0.558 & 0.692 \\
\hline & P value & $0.0001 * *$ & $0.003 * *$ & $0.0001 * *$ & $0.0001 * *$ \\
\hline & Studied groups $\mathrm{N}=$ & 40 & 40 & 40 & 40 \\
\hline \multirow{3}{*}{$\begin{array}{l}\text { Placenta } \\
\text { MicroRNA-16 }\end{array}$} & Correlation coefficient & 0.842 & 0.918 & 0.917 & 0.377 \\
\hline & P value & $0.0001^{* *}$ & $0.0001^{* *}$ & $0.0001 * *$ & $0.016^{*}$ \\
\hline & Studied groups $\mathrm{N}=$ & 40 & 40 & 40 & 40 \\
\hline \multirow{3}{*}{$\begin{array}{l}\text { Serum } \\
\text { MicroRNA-221 }\end{array}$} & Correlation coefficient & -0.775 & -0.889 & -0.910 & -0.393 \\
\hline & P value & $0.001 * *$ & $0.0001 * *$ & $0.0001 * *$ & $0.012 *$ \\
\hline & Studied groups $\mathrm{N}=$ & 40 & 40 & 40 & 40 \\
\hline \multirow{3}{*}{$\begin{array}{l}\text { Placenta } \\
\text { MicroRNA-221 }\end{array}$} & Correlation coefficient & -0.520 & -0.817 & -0.804 & -0.299 \\
\hline & P value & $0.001 * *$ & $0.0001^{* *}$ & $0.0001 * *$ & 0.061 \\
\hline & Studied groups $\mathrm{N}=$ & 40 & 40 & 40 & 40 \\
\hline
\end{tabular}

*: Significant if $(\mathrm{P}<0.05), * *$ : High significant if $(\mathrm{P}<0.001)$.

TABLE 5. Comparison between control, mild GD and severe GD groups in FBG, PPG, BMI, Cholesterol, Fetal birth weight, Serum \& Placenta microRNA-16 and serum \& placental microRNA-221 by using one way-ANOVA

\begin{tabular}{lcccc}
\hline Parameters & $\begin{array}{c}\text { control }(\mathbf{n}=\mathbf{2 0}) \\
\text { Mean } \pm \text { SD }\end{array}$ & $\begin{array}{c}\text { Mild GD(n= 12) } \\
\text { Mean } \pm \text { SD }\end{array}$ & $\begin{array}{c}\text { Severe GD }(\mathbf{n}=\mathbf{8}) \\
\text { Mean } \pm \text { SD }\end{array}$ & P value \\
\hline FBG & $81.60 \pm 5.40$ & $156.66 \pm 35.47$ & $250.10 \pm 53.45$ & $0.001^{* *}$ \\
PPG & $118.30 \pm 11.92$ & $198.90 \pm 10.52$ & $285.00 \pm 37.41$ & $0.001^{* *}$ \\
BMI & $29.62 \pm 2.66$ & $31.29 \pm 3.95$ & $34.27 \pm 4.08$ & $0.027^{*}$ \\
Cholesterol & $187.20 \pm 20.26$ & $255.33 \pm 40.58$ & $251.00 \pm 12.13$ & $0.001^{* *}$ \\
Fetal birth weight & $3260.50 \pm 221.82$ & $3683.33 \pm 251.13$ & $4247.50 \pm 132.9$ & $0.001^{* *}$ \\
Serum MicroRNA-16 & $1.01 \pm 0.015$ & $3.04 \pm 0.96$ & $4.67 \pm 1.62$ & $0.001^{* *}$ \\
Placenta MicroRNA-16 & $1.03 \pm 0.038$ & $4.47 \pm 0.38$ & $6.25 \pm 0.53$ & $0.001^{* *}$ \\
Serum MicroRNA-221 & $1.016 \pm 0.019$ & $0.686 \pm 0.077$ & $0.345 \pm 0.016$ & $0.001^{* *}$ \\
Placenta MicroRNA-221 & $1.006 \pm 0.012$ & $0.213 \pm 0.062$ & $0.205 \pm 0.017$ & $0.001^{* *}$ \\
\hline
\end{tabular}

*: Significant if $(\mathrm{P}<0.05)$, **: High significant if $(\mathrm{P}<0.001)$. 
TABLE 6. Comparison between mild GD subgroup $(n=12)$ and severe GD subgroup $(n=8)$ in biochemical data

\begin{tabular}{|c|c|c|c|c|c|}
\hline Parameter & Group & $\mathbf{N}$ & Mean & Std. deviation & P value \\
\hline \multirow{2}{*}{ FBG } & mild GDM & 12 & 156.66 & 35.47 & $0.001 * *$ \\
\hline & severe GDM & 8 & 250.10 & 53.45 & \\
\hline \multirow{2}{*}{ PPG } & m-GDM & 12 & 198.90 & 10.52 & $0.001 * *$ \\
\hline & s-GDM & 8 & 285.00 & 37.41 & \\
\hline \multirow{2}{*}{ BMI } & m-GDM & 12 & 31.29 & 3.95 & \multirow{2}{*}{0.235} \\
\hline & s-GDM & 8 & 34.27 & 4.08 & \\
\hline \multirow{2}{*}{$\mathrm{HbA1c}$} & m-GDM & 12 & 7.40 & 1.84 & \multirow[t]{2}{*}{$0.038^{*}$} \\
\hline & s-GDM & 8 & 8.70 & 0.585 & \\
\hline \multirow{2}{*}{ Creatinine } & m-GDM & 12 & 0.65 & 0.307 & \multirow[t]{2}{*}{$0.001 * *$} \\
\hline & s-GDM & 8 & 1.100 & 0.160 & \\
\hline \multirow{2}{*}{ INR } & m-GDM & 12 & 0.950 & 0.53 & \multirow[t]{2}{*}{0.278} \\
\hline & s-GDM & 8 & 1.033 & 0.24 & \\
\hline \multirow{2}{*}{ ALT } & m-GDM & 12 & 34.05 & 9.54 & \multirow{2}{*}{0.398} \\
\hline & s-GDM & 8 & 36.50 & 6.53 & \\
\hline \multirow{2}{*}{ Cholesterol } & m-GDM & 12 & 255.33 & 40.58 & \multirow[t]{2}{*}{0.719} \\
\hline & s-GDM & 8 & 251.03 & 12.13 & \\
\hline \multirow{2}{*}{ Fetal birth weight } & m-GDM & 12 & 3683.33 & 251.13 & \multirow[t]{2}{*}{$0.001^{* *}$} \\
\hline & s-GDM & 8 & 4247.50 & 132.9 & \\
\hline \multirow{2}{*}{$\begin{array}{l}\text { SerumMicro } \\
\text { RNA-16 }\end{array}$} & m-GDM & 12 & 3.04 & 0.96 & \multirow[t]{2}{*}{$0.028^{*}$} \\
\hline & s-GDM & 8 & 4.67 & 1.62 & \\
\hline \multirow{2}{*}{$\begin{array}{l}\text { PlacentaMicro } \\
\text { RNA-16 }\end{array}$} & m-GDM & 12 & 4.47 & 0.38 & \multirow{2}{*}{$0.001 * *$} \\
\hline & s-GDM & 8 & 6.25 & 0.53 & \\
\hline \multirow{2}{*}{ SerumMicro RNA-221 } & m-GDM & 12 & 0.686 & 0.077 & \multirow[t]{2}{*}{$0.001 * *$} \\
\hline & s-GDM & 8 & 0.345 & 0.016 & \\
\hline PlacentaMicro & m-GDM & 12 & 0.213 & 0.062 & . \\
\hline RNA-221 & s-GDM & 8 & 0.205 & 0.017 & 0.668 \\
\hline
\end{tabular}

*: Significant if $(\mathrm{P}<0.05), * *$ : High significant if $(\mathrm{P}<0.001)$.

\section{Discussion:}

MicroRNAs are small noncoding $\sim 19-24$ nucleotide that play an important role in the modulation of gene expression (Bartel, 2004). It has been hypothesized that approximately $60 \%$ of genes are regulated by microRNAs; thus, these molecules are critically involved in the regulation of many biological processes (Morris \& Mattick, 2014). The characterization of placental microRNAs could be essential to understand the regulatory mechanisms of normal and complicated pregnancies (Cai et al., 2017).

According to the studies done by Cao and colleagues (2017), which reported that plasma microRNA-16-5p was significantly upregulated at different times during pregnancy in GDM. On the other hand, Li et al. study in (2009) identified a novel pathway by which hyperglycemic conditions impair c-kit expression and migration of human umbilical vein endothelial cells through induction of miR-221, and reported that manipulation of the miR-221-c-kit path may propose a new approach for management of vascular dysfunction in diabetic patients. Hence, The authors focused in this study on MicroRNA-16 and microRNA-221 expression in both serum and placental tissue with their correlation with the fetal macrosomia to detect their role in GDM and detect whether they could be used as biomarkers to identify women at risk of developing severe GDM and macrosomic infants. In the present study, in GDM group, the placental homogenate microRNA-16 levels are higher than those in the maternal serum microRNA-16, which could be explained by the fact that it originated by the placenta, and might be responsible for the occurrence of macrosomia (Filardi et al., 2020). However, it is not the case with microRNA-221 which 
decreased in placental homogenate of the GDM group than in maternal serum and its level was lower than in the control group, as this might be a protective mechanism to prevent complications of its increasing levels on the placental circulation and therefore on the fetus. Another interpretation is that perhaps the upregulation in some microRNAs as the microRNA-16 in this study decreases the expression of others like the case in microRNA-221 to prevent severe vascular complications associated with high microRNA-221 (Zhao \& Tao, 2019).

As regards to microRNA-16 in this study, there was a high significant increase in serum and placental microRNA-16 expression in GDM group than in the control group. This microRNA-16 whose expression increased in serum of severe GDM patients may increase diabetogenic factors in mothers. This increase in the placenta of GDM more than in the serum may potentially be linked to placental functions, development and increase of growth factors that are responsible for macrosomia and hence the increase in macrosomic fetuses in severe GDM group than in mild GDM group. This comes in accordance to Cao et al. (2017) who confirmed the results of the pilot study by Zhu et al. (2015) in a larger group of patients by analyzing the same differentially expressed microRNAs amongst which was miR16-5p, which was progressively upregulated during pregnancy in the plasma samples of GDM women at $16^{\text {th }}-19^{\text {th }}$ week, $20^{\text {th }}-24^{\text {th }}$ week, and 24th-28th week of pregnancy (Cao et al., 2017). Their findings support the suggestion that miR$16-5 p$ is one of the best predictors of gestational diabetes. Although some studies reported the involvement of miR-16-5p in type 2 diabetes (T2D) and in other metabolic diseases, other studies demonstrated that miR-16-5p targeted genes (CUL4A, SMAD1, EGFR, ACTB, RRP12, and $D A B 2$ ) have been reported to be downregulated in T2D (Calimlioglu et al., 2015), which may be responsible for small for gestational age born infants in type 2 diabetes mellitus mothers. On the other hand, the present study differs in its results from the findings of Hocaoglu and his colleagues (2019) whose study for the first time revealed that miR-16-5p, was not related to pregnancy complicated with neither preeclampsia nor GDM as they were not differentially expressed in these pregnancy disorders as compared to healthy pregnancy. Also, in contrary to the current findings, Pheiffer et al.
(2018) reported conflicting results, stating that the expression of plasma miR-16-5p was decreased in South African women with GDM.

In GDM group, it was found that macrosomia was directly significantly correlated with microRNA-16-5p. This means that increased levels of microRNA-16 in serum of mothers and in placental homogenate are associated with macrosomia. The present results could be explained by suggestion that the increase in microRNA-16 could be responsible for large fetuses in GDM pregnancies. These results were in agreement with the results of Ge et al. (2015) who reported that the expression of miR-16 increased in the plasma of pregnant women with fetal macrosomia compared to normal the controls. However, another study conducted by Jiang et al. (2014) did not find any significant differences in miR-16 expression levels in mothers between macrosomia group and the control group.

The present study showed that there were significant decreases in serum and placental microRNA-221 expression levels in mild GDM and severe GDM than in the control group. This could be due to pregnancy protective factors in mothers, and its decrease in the placentas of GDM patients than in their serum that may potentially be linked to protective mechanisms controlled by other factors acting upon endothelium of the vessels to maintain adequate blood supply in the placenta to the fetus. The present results came in agreement with the study of Ge et al. (2015) who reported that the expression of miR-221 decreased in the plasma of pregnant women with fetal macrosomia compared to the normal controls, further supporting the use of miRNAs as predictive biomarkers for pregnancy complications. Moreover, the results of this study come in accordance to the results of Zhao \& Tao (2019) who reported that MicroRNA-221 decreased in placental homogenate of GDM rats, and its level was correlated negatively to that of the blood glucose level in GDM rats versus the controls. However, the current results are in contrary to Díaz-Pérez et al. (2016) who found that microRNA-221 to be upregulated in human fetoplacental endothelial cells isolated from third-trimester human placentas after pregnancies complicated by GDM versus healthy pregnancies. They suggested this mechanism as protection against leucocyte transmigration from blood to placenta which may worsen the inflammation 
due to hyperglycemia during GDM. The first study demonstrating a specific case of placenta-blood mirroring in GDM and involving microRNAs has been performed by $\mathrm{Xu}$ and colleagues. They suggested the possibility of a microRNA-based specific cross talk between placenta and $\beta$ cells in gestational diabetes (Xu et al., 2017).

Hromadnikova et al. (2020) in a recent study reported that children with a prior exposure to GDM are at higher risk of later development of diabetes mellitus and cardiovascular/cerebrovascular diseases, and would benefit from implementation of primary prevention strategies.

The role of these upregulated microRNAs in the pathogenesis of GDM are not yet fully understood. It had been well recognized that no single microRNA or signaling pathway could be responsible for the occurrence of the GDM (Monfared et al., 2018). Maintaining homoeostasis in many organs, including the placenta, was established by microRNAs through targeting a large number of genes and participating in various cellular events. The identification of dysregulated microRNAs in GDM placentas and the clarification of gene networks that were regulated by those microRNAs would likely be novel steps in understanding the pathogenesis of such compromised pregnancies (Szmuilowicz et al., 2019).

\section{Conclusion}

The present study documented the elevation of microRNA-16 in maternal serum of GDM group and its higher level in placenta. On the contrary, the authors observed reduction of microRNA-221 in the serum of GDM group and in placenta compared to the control group. Another finding was the significant direct correlation of microRNA-16 in maternal serum and placenta with the severity of GDM and with macrosomia, which is not the case with microRNA-221. The present findings agreed with the findings, which proposed microRNA-16 as a diagnostic biomarker to identify women at risk of developing severe GDM and macrosomic infants.

Recommendations: Further studies are needed to clarify the role of the elevated microRNA- 16 and microRNA-221 in GDM and their relation to etiology, pathophysiology, the aggravation of this condition and their role in developing macrosomia.

Acknowledgement: Thanks to Dr. Laila Rashed, professor of Biochemistry, Faculty of Medicine, Cairo University, for her help in biochemical analysis of all parameters.

Declaration of interest: The authors report no conflicts of interest. The authors are solely responsible for the content and writing of the paper. The authors did not receive any grant.

\section{References}

ACOG Practice Bulletin (2010) Number 216, Macrosomia. Obstetrics \& Gynecology: January 2020 - 135 - Issue 1 - 18-35.

Akgöl, E., Abuşoğlu, S., Gün, F.D., Ünlü, A. (2017) Prevalence of gestational diabetes mellitus according to the different criterias. Turk J. Obstet. Gynecol. 14, 1822.

Bartel, D.P. (2004) MicroRNAs: Genomics, biogenesis, mechanism, and function. Cell, 116(2), 281-297.

Bartel, D.P. (2009) MicroRNAs: Target recognition and regulatory functions. Cell, 136(2), 215-33.

Basina, M. (2012) Gestational diabetogenesis. J. Women's Health Care, 01, e106.

Cai, M., Kolluru, G.K., Ahmed, A. (2017) Small molecule, big prospects: microrna in pregnancy and its complications. Journal of Pregnancy, 2017, 1-15.

Calimlioglu, B., Karagoz, K., Sevimoglu, T., Kilic, E., Gov, E., Arga, K.Y. (2015) Tissue-specific molecular biomarker signatures of type 2 diabetes: an integrative analysis of transcriptomics and protein-protein interaction data. OMICS: A Journal of Integrative Biology, 19(9), 563-573.

Cao, Y.L., Jia, Y.J., Xing, B.H., Shi, D.D., Dong, X.J. (2017) Plasma microRNA-16-5p, -17-5p and -20a$5 \mathrm{p}$ : Novel diagnostic biomarkers for gestational diabetes mellitus. J. Obstet. Gynaecol. Res. 43(6), 974-981.

Catalano, P.M. (2014) Trying to understand gestational diabetes. Diabet. Med. 31, 273-281.

Coskunpinar, E., Cakmak, H.A., Kalkan, A.K., Tiryakioglu, N.O., Erturk, M., Ongen, Z. (2016) Circulating miR-221-3p as a novel marker for early prediction of acute myocardial infarction. Gene. 591, 90-96. 
Dabelea, D., Hanson, R.L., Lindsay, R.S., et al. (2000) Intrauterine exposure to diabetes conveys risks for type 2 diabetes and obesity: A study of discordant sibships. Diabetes, 49, 2208-2211.

Derda, A.A., Pfanne, A., Bwangär, C., Schimmel, K., Kennel, P.J., Xiao, K., Schulze, P.C., Bauersachs, J., Thum, T. (2018) Blood-based microRNA profiling in patients with cardiac amyloidosis. PLOS ONE, 13, e0204235.

Díaz-Pérez, F.I., Hiden, U., Gauster, M., et al. (2016) Post-transcriptional down regulation of ICAM-1 in feto-placental endothelium in GDM. Cell Adhesion \& Migration, 10(1-2), 18-27.

Dolz, S., Górriz, D., Tembl, J.I., Sánchez, D., Fortea, G., Parkhutik, V., Lago, A. (2017) Circulating microRNAs as novel biomarkers of stenosis progression in asymptomatic carotid stenosis. Stroke, 48, 10-16.

England, L.J, Dietz, P.M., Njoroge, T., et al. (2009) Preventing type 2 diabetes: Public health implications for women with a history of gestational diabetes mellitus. Am. J. Obstet. Gynecol. 200, 365. e361-365.e368.

Eyth, E., Basit, H., Smith, C.J. (2020) Glucose tolerance test. [Updated 2020 Aug 11]. In: StatPearls [Internet]. Treasure Island (FL): StatPearls Publishing; 2020 Jan.Available from: https://www. ncbi.nlm.nih.gov/books/NBK532915/

Ferrara, A. (2007) Increasing prevalence of gestational diabetes mellitus: A public health perspective. Diabetes Care, 30(Suppl. 2), S141-S146.

Filardi, T., Catanzaro, G., Mardente, S., Zicari, A., Santangelo, C., Lenzi, A., Morano, S., Ferretti, E. (2020) Non-coding RNA: Role in gestational diabetes pathophysiology and complications. Int. J. Mol. Sci. 21, 4020.

Ge, Q., Zhu, Y., Li, H., Tian, F., Xie, X., Bai, Y. (2015) Differential expression of circulating miRNAs in maternal plasma in pregnancies with fetal macrosomia. International Journal of Molecular Medicine, 35, 81-91.

Guarino, E., Poggi, C.D., Grieco, G.E., Cenci, V., Ceccarelli, E., Crisci, I., Sebastiani, G., Dotta, F. (2018) Circulating MicroRNAs as biomarkers of gestational diabetes mellitus: Updates and perspectives. Int. J. Endocrinol. 2018, 6380463.

Gusar, V.A., Timofeeva, A.V., Zhanin, I.S., Shram, S.I., Pinelis, V.G. (2017) Estimation of timedependent microRNA expression patterns in brain tissue, leukocytes, and blood plasma of rats under photochemically induced focal cerebral ischemia. Mol. Biol. 51, 683-695.

Hocaoglu, M., Demirer, S., Senturk, H., Turgut, A., Komurcu-Bayrak, E. (2019) Differential expression of candidate circulating microRNAs in maternal blood leukocytes of the patients with preeclampsia and gestational diabetes mellitus. Pregnancy Hypertension, 17, 5-11.

Hromadnikova, I., Kotlabova, K., Dvorakova, L., Krofta, L., Sirc, J. (2020) Substantially altered expression profile of diabetes/cardiovascular/ cerebrovascular disease associated microRNAs in children descending from pregnancy complicated by gestational diabetes mellitus-one of several possible reasons for an increased cardiovascular risk. Cells, 9(6), 1557.

Ilekis, J.V., Tsilou, E., Fisher, S., Abrahams, V.M., Soares, M.J., Cross, J.C., et al. (2016) Placental origins of adverse pregnancy outcomes: potential molecular targets: An executive workshop summary of the eunicekennedyshriver national institute of child health and human development. Am. J. Obstet. Gynecol. 215(1 Suppl), S1S46.

Jiang, H., Wu, W., Zhang, M., Li, J., Peng, Y., Miao, T., Zhu, H., Xu, G. (2014) Aberrant upregulation of miR-21 in placental tissues of macrosomia. Journal of Perinatology, 34, 658-663

Karcaaltincaba, D., Calis, P., Ocal, N., Ozek, A., AltugInan, M., Bayram, M. (2017) Prevalence of gestational diabetes mellitus evaluated by universal screening with a $75 \mathrm{~g}, 2 \mathrm{~h}$ oral glucose tolerance test and IADPSG criteria. Int. J. Gynecol. Obstet. 138, 148151.

Krol, J., Loedige, I., Filipowicz, W. (2010) The widespread regulation of microRNA biogenesis, function and decay. Nat. Rev. Genet. 11, 597-610.

Lawrence, J.M., Contreras, R., Chen, W., Sacks, D.A. (2008) Trends in the prevalence of preexisting diabetes and gestational diabetes mellitus among a racially/ethnically diverse population of pregnant women, 1999-2005. Diabetes Care, 31, 899-904. 
Li, L.J., Yu, Q. (2019) Ipramho-International Study Group. Tan KH. Clinical practice of diabetic pregnancy screening in Asia-Pacific Countries: A survey review. Acta Diabetol. 56(7), 815-817.

Li, Y., Song, Y.H., Li, F., Yang, T., Lu, Y.W., Geng, Y.J. (2009) MicroRNA-221 regulates high glucoseinduced endothelial dysfunction. Biochem. Biophys. Res. Commun. 381(1), 81-83.

Monfared, Y.K., Ghadimi, F., Foroughi, F., Honardoost, M., Hashemipour, S., Sefidi, F., Sarookhani, M.R. (2018) Determination and comparison miR135a in the serum between women with GDM, non-pregnant type 2 diabetes, healthy pregnant and control group. Middle East J. Fam. Med. 2, 193-197.

Morris, K.V., Mattick, J.S. (2014) The rise of regulatory RNA. Nature Reviews Genetics, 15(6), 423-437.

Nie, X., Chen, Y., Tan, J., Dai, Y., Mao, W., Qin, G., Ye, S., Sun, J., Yang, Z., Chen, J. ( 2019) MicroRNA-2213 p promotes pulmonary artery smooth muscle cells proliferation by targeting AXIN2 during pulmonary arterial hypertension. Vascul. Pharmacol. 116, 24-35.

O’Sullivan, J.B. (1982) Body weight and subsequent diabetes mellitus. JAMA, 248, 949-952.

Pereira-da-Silva, T., Coutinho Cruz, M., Carrusca, C., Cruz Ferreira, R., Napoleão, P., Mota Carmo, M. (2018) Circulating microRNA profiles in different arterial territories of stable atherosclerotic disease: A systematic review. Am. J. Cardiovasc. Dis. 8, 1-13.

Pheiffer, C., Dias, S., Rheeder, P., Adam, S. (2018) Decreased expression of circulating miR-20a-5p in south African women with gestational diabetes mellitus. Molecular Diagnosis \& Therapy, 22, 345352.

Pillar, N., Yoffe, L., Hod, M., Shomron, N. (2015) The possible involvement of microRNAs in preeclampsia and gestational diabetes mellitus. Best Pract. Res. Clin. Obstet. Gynaecol. 29, 176182.

Powe, C.E. (2017) Early pregnancy biochemical predictors of gestational diabetes mellitus. Curr. Diab. Rep. 17(2), 12.

Renz, P.B., Chume, F.C., Timm, J.R.T., Pimentel, A.L., Camargo, J.L. (2019) Diagnostic accuracy of glycated hemoglobin for gestational diabetes mellitus: A systematic review and meta-analysis. Clin. Chem. Lab. Med. 57(10), 1435-1449.

Rodrigo, N., Glastras, S.J. (2018) The emerging role of biomarkers in the diagnosis of gestational diabetes mellitus. J. Clin. Med. 7(6), 120.

Song, J.J., Smith, S.K., Hannon, G.J., Joshua-Tor, L. (2004) Crystal structure of Argonaute and its implications for RISC slicer activity. Science, $\mathbf{3 0 5}$, 1434-1437.

Sørensen, S.S., Nygaard, A.B., Nielsen, M.Y., Jensen, K., Christensen, T. (2014) miRNA expression profiles in cerebrospinal fluid and blood of patients with acute ischemic stroke. Transl. Stroke Res. 5, 711-718.

Su, H., Trombly, M.I., Chen, J., Wang, X., (2009) Essential and overlapping functions for mammalian Argonautes in microRNA silencing. Genes. Dev. 23, 304-317.

Szmuilowicz, E.D., Josefson, J.L., Metzger, B.E. (2019) Gestational Diabetes Mellitus. Endocrinol. Metab. Clin. North Am. 48, 479-493.

Verjans, R., Peters, T., Beaumont, F.J., van Leeuwen, R., van Herwaarden, T., Verhesen, W., Munts, C., Bijnen, M., Henkens, M., Diez, J., et al. (2018) MicroRNA-221/222 family counteracts myocardial fibrosis in pressure overload-induced heart failure. Hypertension, 71, 280-288.

Villard, A., Marchand, L., Thivolet, C., Rome, S. (2015) Diagnostic value of cell-free circulating microRNAs for obesity and type 2 diabetes: A meta-analysis. J. Mol. Biomark. Diagn. 6, 251.

Wang, Y., Juranek, S., Li, H., Sheng, G., Wardle, G.S., Tuschl, T., Patel, D.J. (2009) Nucleation, propagation and cleavage of target RNAs in Ago silencing complexes. Nature, 461, 754-761.

Xu, K., Bian, D., Hao, L., et al. (2017) MicroRNA-503 contribute to pancreatic beta cell dysfunction by targeting the mTOR pathway in gestational diabetes mellitus. EXCLI Journal, 16, 1177-1187.

Yekta, S., Shih, I.H., Bartel, D.P. (2004) MicroRNAdirected cleavage of HOXB8 mRNA. Science, 304, 594-596.

Zhao, H., Tao, S. (2019) MiRNA-221 protects islet $\beta$ 
cell function in gestational diabetes mellitus by targeting PAK1. Biochemical and Biophysical Research Communications, 520, 1, 218-224.

Zhu, Y., Tian, F., Li, H., Zhou, Y., Lu, J., Ge, Q. (2015) Profiling maternal plasma microRNA expression in early pregnancy to predict gestational diabetes mellitus. Int. J. Gynaecol. Obstet. 130, 49-53.
Zhuang, X., Li, R., Maimaitijiang, A., Liu, R., Yan, F., Hu, H., Gao, X., Shi, H. (2019) miR-221-3p inhibits oxidized low-density lipoprotein induced oxidative stress and apoptosis via targeting a disintegrin and metalloprotease-22. J. Cell Biochem. 120, 63046314. 